\title{
Influence of Tread Width of the Brake Pedal Pads on the Friction Coefficient Generated by Bare Foot and Footwear Soles
}

\author{
Al-Osaimy A. S. and Ali W. Y. \\ Faculty of Engineering, Taif University, Al-Taif, Saudi Arabia \\ alosaimy@tu.edu.sa\&wahyos@hotmail.com
}

\begin{abstract}
The present work discusses the effect of the treads width of the rubber brake pedal pads on the friction coefficient. Measurement of friction coefficient generated by bare foot and rubber footwear soles sliding against the brake pedal pads of different treads width in dry, sand contaminated, water and oil lubricated conditions is discussed.
\end{abstract}

Experiments of the sliding of bare foot against the rubber pedal pad showed that friction coefficient of dry sliding significantly decreased with increasing tread width. The sliding direction has no effect on the friction coefficient for the tested pads. In the presence of sand particles separating the two contact surfaces, load had no influence on friction coefficient. Friction coefficient slightly decreased with increasing tread width. For water wetted pedal pad, friction coefficient displayed higher values than that observed for the condition of presence of sand particles. Friction values showed consistent trend with increasing the tread width. Friction displayed by oil lubricated pedal pads was the lowest and the sliding condition could be considered as unsafe.

When rubber shoes slide against the tested rubber pads friction coefficient displayed relatively lower values than bare foot. Sliding in the transverse direction displayed higher friction values than longitudinal one at dry sliding. In the presence of sand particles on the sliding surfaces, the shortest tread width displayed the highest friction. Sliding against water wetted pedal pad, the highest values of friction coefficient were displayed by $2 \mathrm{~mm}$ tread width due to the water leakage from the contact area. The friction values displayed in the transverse direction were relatively lower than that observed in the longitudinal one. Besides, sliding against oil lubricated pedal pad 
showed relatively low friction values which were considered as unsafe sliding.

Keywords: Friction, bare foot, Rubber footwear soles, Rubber brakepedal pad, Rubber treads width.

\section{Introduction}

In condition of stomping down on the brake pedal, an acceptable value of friction should be obtained to keep the foot from slipping off. When stepping on a contaminated brake pedal pads, neither the shoe sole nor the bare foot are able to touch the pad surface without squeezing the contaminants out of the contact area. Little attention was exerted to measure the friction coefficient of rubber footwear soles sliding against dry and contaminated brake pedal pads. The majority of previous researches studied the frictional behaviour of the sliding of bare foot as well as foot wear soles against different types of floorings ${ }^{[1-16]}$. Soft material like rubber tends to a higher effective contact area and more pronounced microscopic deformations when mechanically interacting with the surface asperities of a rigid material, greater friction coefficients can be expected for rubber than for plastic ${ }^{[1]}$. This was found in the friction measurement under wet conditions. In general, rubber friction is divided into two parts; the bulk hysteresis and the contact adhesive term $^{[2]}$. These two contributions are regarded to be independent of each other, but this is only a simplified assumption.

Friction measurement is one of the major approaches to quantify floor slipperness. Investigations on friction measurement have been focused on liquid contaminated conditions. It was expected that wet surfaces had significant lower friction coefficient values than those of the dry surfaces ${ }^{[3]}$. The friction coefficient difference between the dry and wet surfaces depended on the footwear material and floor combinations. Friction measurements under liquid-contaminated conditions were very common. The squeeze film theory explains the effects of the liquid on the measured friction. Measurements of the static friction coefficient between rubber specimens and ceramic surfaces were carried out at dry, water lubricated, oil, oil diluted by water and sand contaminating the lubricating fluids ${ }^{[4-7]}$. It was observed that, dry sliding of the rubber test specimens displayed the highest value of friction coefficient. For water lubricated ceramics, the value of the friction coefficient decreased compared to dry sliding. For oil lubricated ceramic, friction coefficient 
decreased with increasing height of the grooves introduced in the rubber specimens. As for ceramic lubricated by detergent and contaminated by sand, friction coefficient increased significantly compared to the sliding conditions of water and soap only.

The effect of the treads width and depth of the shoe sole on the friction coefficient between the shoe and ceramic floor interface was discussed ${ }^{[8]}$. It was found that, at dry sliding, friction coefficient slightly increased with increasing treads height. In the presence of water on the sliding surface a significant decrease in friction coefficient was observed compared to the dry sliding. For detergent wetted surfaces, friction coefficient drastically decreased to values lower than that displayed by water. Oily smooth surfaces gave the lowest friction value as a result of the presence of squeeze oil film separating rubber and ceramic. Emulsion of water and oil shows slight friction increase compared to oil lubricated sliding. Besides, friction coefficient significantly increased up to maximum then slightly decreased with increasing the treads height. At water, detergent and oil lubricated sliding conditions, friction coefficient decreased as the tread width increased due to the increased area of the fluid film. The friction decrease may be due to the increased ability of the tread to form hydrodynamic wedge as the tread width increased. Tread groove designs are helpful in facilitating contact between the shoe sole and floor on liquid contaminated surface ${ }^{[9-12]}$. The effectiveness of a tread groove design depends on the contaminant, footwear material and floor. Tread groove design was ineffective in maintaining friction on a floor covered by vegetable oil. Tread grooves should be wide enough to achieve better drainage capability on wet and water detergent contaminated floors.

The factors affecting friction coefficient measurement are the material, surface geometry of the footwear as well as floor, floor contamination conditions and even the slipmeter used ${ }^{[13-17]}$. Investigators have concentrated the friction coefficient measurements on liquid contaminated floors because most slip/fall incidents occur on the surfaces of such floors ${ }^{[18-21]}$. When stepping on a wet or lubricated floor, a shoe sole cannot touch the floor surface without squeezing the liquid out of the contact area. The liquid between the floor and the sole isolates the two contact surfaces, thus reducing the friction between them. The liquid drainage time between the two contact surfaces depends on the viscosity and pressure between the two surfaces. The higher the viscosity is, the 
longer the time is required for the film thickness to decrease ${ }^{[22]}$. A longer drainage time increases the risk of slipping due to the short time available to prevent a slip after the heel touches the floor.

The effect of surface roughness of ceramic on the friction coefficient, when rubber and leather are sliding against it, was investigated ${ }^{[23]}$. Glazed floor tiles of different roughness ranging from 0.05 and $6.0 \mu \mathrm{m}$ were tested. The test results showed that, friction coefficient decreased down to minimum then increased with increasing the surface roughness of the ceramic surface.

The effect of surface hardness of the brake pedal pads on the friction coefficient was discussed ${ }^{[24]}$. It was found that for bare foot sliding against the pedal pads, at dry sliding, friction coefficient slightly decreased with increasing the hardness of the rubber pad. For the transverse direction of sliding, friction coefficient displayed relatively lower values than that observed for longitudinal sliding. In the presence of sand particles between the foot and the rubber pad, friction coefficient increased significantly with increasing the hardness. For contaminated sliding surfaces, it was noticed that the tread sliding direction had no influence on the friction values. Bare foot against water wetted pedal pads displayed friction coefficient relatively higher than that shown for surfaces contaminated by sand particles. For oil lubricated pedal pad, friction coefficient significantly increased with increasing the hardness of the rubber pad, at longitudinal and transverse directions respectively. Transverse sliding direction displayed relatively higher friction values than the longitudinal one. Rubber footwear soles slide against the tested pedal pads displayed lower friction values than that observed for bare foot at dry sliding. In the presence of sand particles on the sliding surfaces, friction coefficient significantly increased, while decreased for water wetted pads with increasing the hardness of the tested pad. Friction coefficient of rubber footwear soles sliding against oil lubricated pedal pad increased with increasing the hardness of the rubber pad. The values of friction coefficient were relatively lower than that displayed by bare foot. It seems that rubber surface stored oil film area more efficiently than the bare foot.

In the present work, the friction coefficient of brake pedal pads of different tread width was tested when sliding against bare foot and rubber footwear at dry, water, oil and sand contaminated sliding conditions. 


\section{Experimental}

Experiments were carried out using a test rig to measure the friction coefficient displayed by bare foot as well as footwear soles sliding against the tested brake pedal pads through measuring the friction and normal forces. The tested brake pedal pads were adhered in a base supported by two load cells, the first could measure the horizontal force (friction force) and the second could measure the vertical force (normal load). Friction coefficient is determined by the ratio between the friction and the normal forces. The arrangement of the test rig is shown elsewhere ${ }^{[1]}$. The tested brake pedal pads were thoroughly cleaned with soap water to eliminate any dirt and dust and carefully dried before the tests. The directions of the sliding are shown in Fig. 1. The tested pads were adhered to the base of the test rig, where bare foot and shoes were loaded against them to determine friction coefficient, Fig. 2. Friction test was carried out at different values of normal load exerted by foot. The relationship between friction coefficient and load was plotted for every test for load ranged from 0 to $700 \mathrm{~N}$. Then the values of friction coefficient were extracted from the figures at loads of 50, 100, 150 and $200 \mathrm{~N}$.

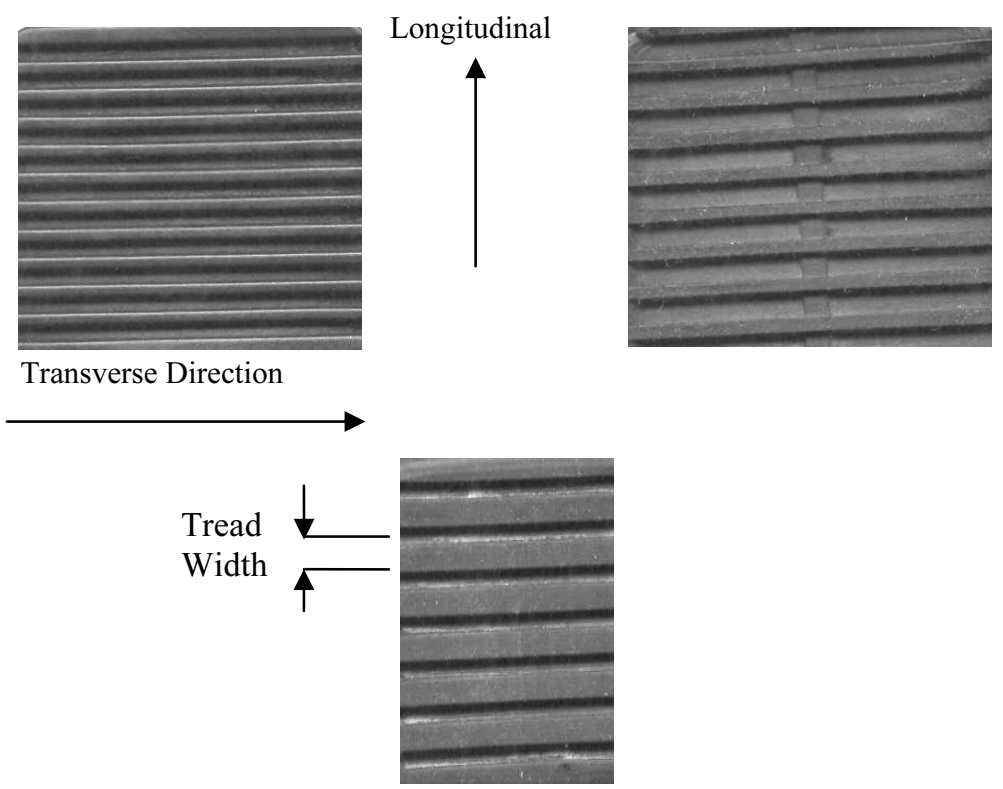

Fig. 1. Brake pedal pads of different tread widths. 


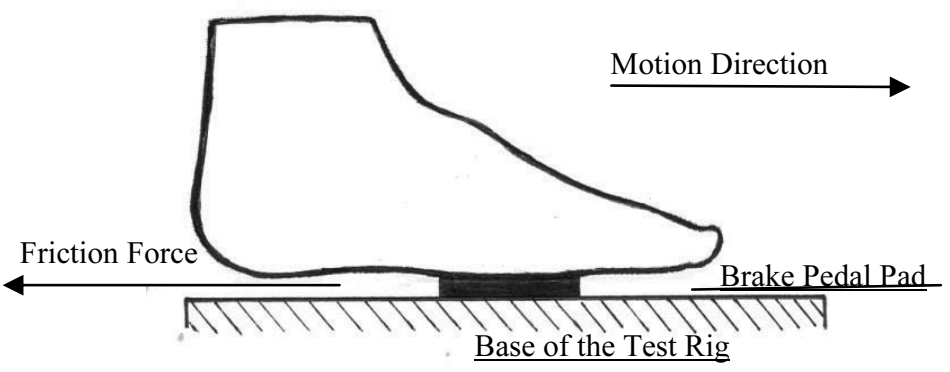

Fig. 2. Arrangement of the test rig.

It is planned in the present work to measure the friction coefficient displayed by bare foot sliding against brake pedal pads. This is due to the behaviour of some people, in tropical countries, that used to drive their cars without footwear. The sliding conditions tested in the experiment were dry, water lubricated, oil, and sand contaminating the sliding surfaces of bare foot, rubber footwear shoes of smooth surface and the tested pads of different tread width of 2, 3.5, 6 and $8 \mathrm{~mm}$. The hardness of the rubber pads is 65 Shore A. Foot and footwear soles were washed by detergent to remove perspiration from the foot skin and footwear soles then carefully dried before the test. For the contaminated surfaces, water and oil were replenished on the bare foot, footwear soles and the tested pedal pad, where the amount for each replenishment was $10 \mathrm{ml}$ to form consistent liquid film covering the sliding surfaces. After the wet test, all contaminants were removed from the tested sliding surfaces using absorbent papers. The tested pads were then washed by detergent, rinsed using water and blown using hair dryer after the cleaning process. Sand particles used in the experiments were silica of $0-80 \mu \mathrm{m}$ particle size. Vegetables oil (corn oil) was used as liquid contaminant.

\section{Results and Discussion}

The results of experiments carried out to measure the friction coefficient displayed by the sliding of bare foot against the brake pedal pads are shown in Fig. 3-6 and 8-11. Friction coefficient of dry sliding of bare foot against the pedal pad in the longitudinal direction significantly decreased with increasing the tread width, Fig. 3. It seems that as the tread width increased the deformation of the rubber surface decreased and consequently friction coefficient decreased. That behaviour is attributed to the fact that friction force displayed by rubber has two 
components, adhesion and deformation. The deformation component results from the internal rubber friction, while adhesion will deform the rubber at the pedal pad surface, where rubber follows the shortwavelength surface roughness profile. This gives an additional contribution to the friction force. Generally, friction coefficient decreased with increasing the load. Pads of $2 \mathrm{~mm}$ tread width displayed the highest friction values of 1.08, 0.95, 0.92 and 0.88 at applied loads of 50, 100, 150 and $200 \mathrm{~N}$ respectively. This relatively high friction is attributed to the very low elastic modulus of rubber and its high internal friction. The change in friction values for transverse dry sliding was negligible, Fig. 4. It can be mentioned that, at dry sliding the sliding direction has no effect on the friction coefficient for the tested pads.

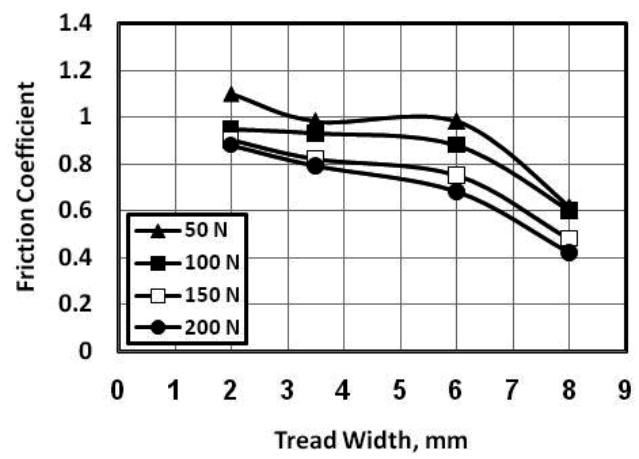

Fig. 3. Friction coefficient of dry sliding of bare foot against the pedal pad. Longitudinal direction.

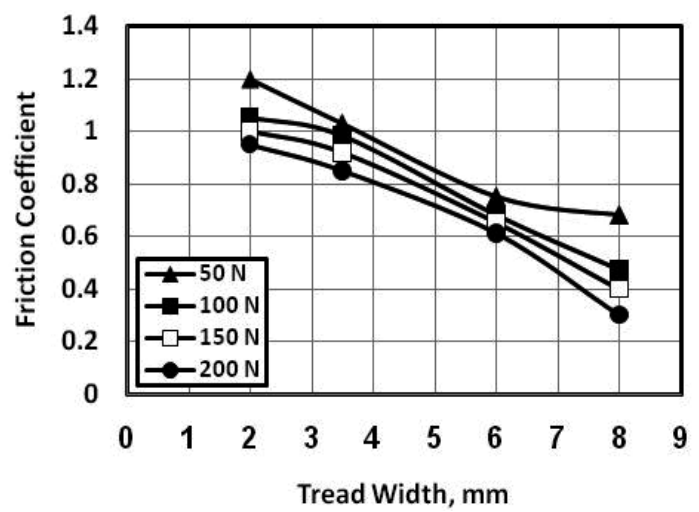

Fig. 4. Friction coefficient of dry sliding of bare foot against the pedal pad. Transverse direction. 
Friction coefficient of bare foot sliding against sand contaminated pedal pad in the longitudinal direction is shown in Fig. 5. The load had no influence on friction coefficient due to the presence of sand particles separating the two contact surfaces. Friction coefficient slightly decreased with increasing the tread width. This behaviour may be attributed to the increased area of the contact surfaces of both bare foot and rubber pads that were embedded by sand particles. The rolling mechanism of sand particles may be responsible for the slight decrease in friction. In transverse direction, Fig. 6, similar values of friction coefficient were displayed confirming that the sliding direction had no effect on the friction when sand particles are separating the two contact surfaces. Figure 7 shows sand particles trapped between the two sliding surfaces where the friction was between sand and the two sliding surfaces.

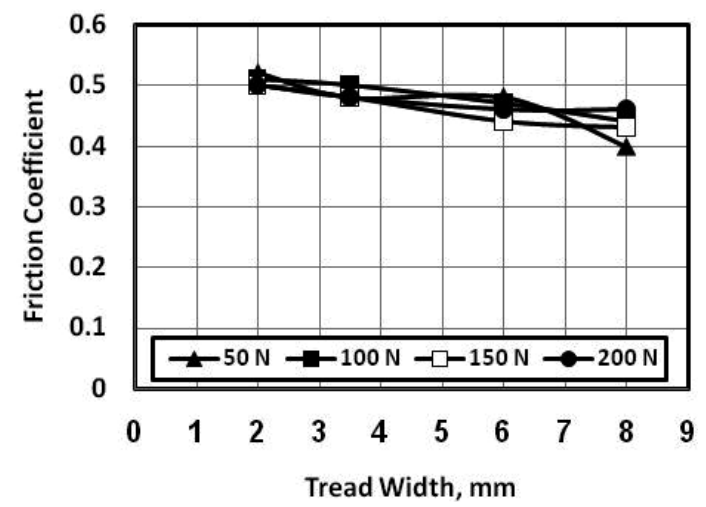

Fig. 5. Friction coefficient of bare foot sliding against sand contaminated pedal pad. Longitudinal direction.

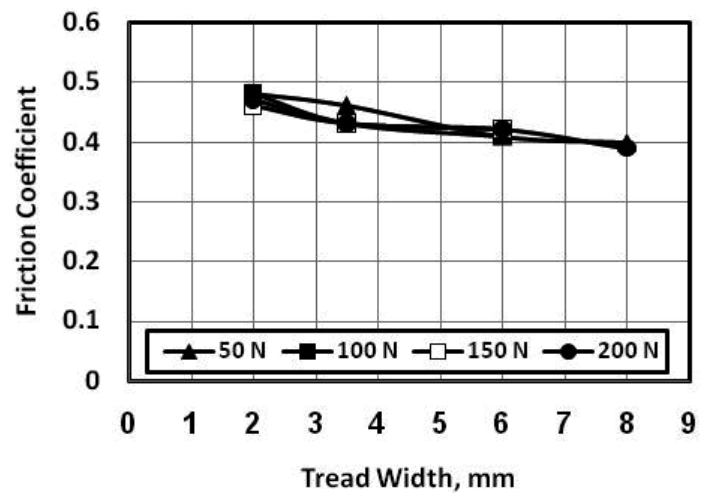

Fig. 6. Friction coefficient of bare foot sliding against sand contaminated pedal pad. Transverse direction. 


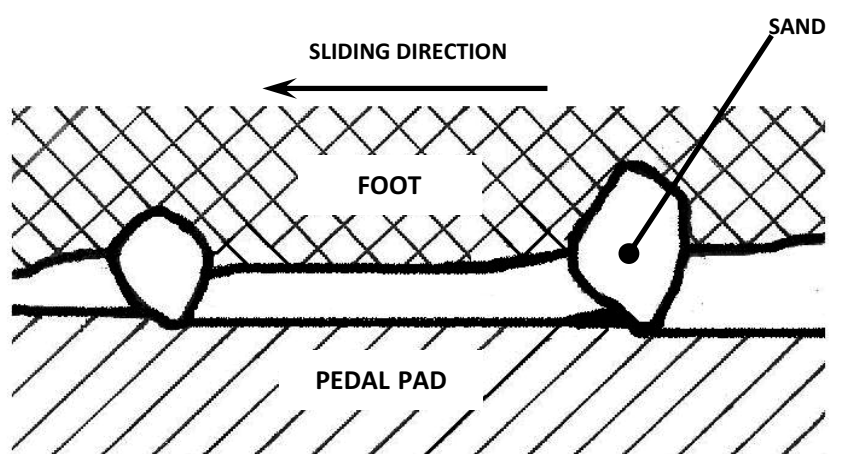

Fig. 7. Sand particles trapped between the two sliding surfaces.

For water wetted pedal pad, friction coefficient displayed higher friction values than that observed for surfaces contaminated by sand particles, Fig. 8. Friction values showed consistent trend with increasing the tread width due to the easy water escape away of the contact surfaces. In the transverse direction friction slightly decreased with increasing the tread width due to the increased ability of water film formation along the tread length, Fig. 9. For the range of the tread width tested in the present work, friction coefficient was above 0.6 .

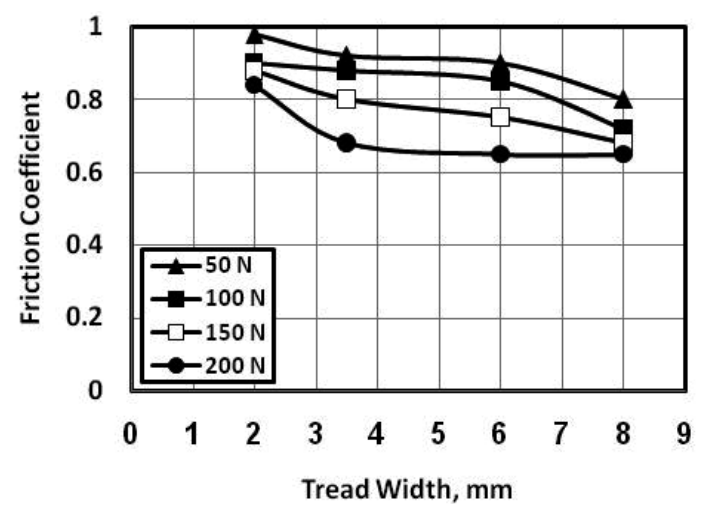

Fig. 8. Friction coefficient of bare foot sliding against water wetted pedal pad. Longitudinal direction. 


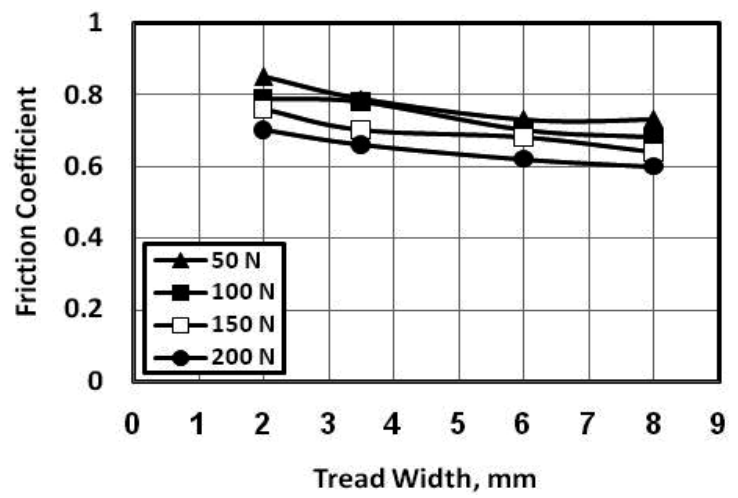

Fig. 9. Friction coefficient of bare foot sliding against water wetted pedal pad. Transverse direction.

Friction coefficient of bare foot sliding against oil lubricated pedal pad in the longitudinal and transverse directions is shown in Fig. 10 and 11. Generally, friction displayed by oil lubricated pedal pads was the lowest among the other sliding conditions. Friction coefficient decreased with increasing tread width. Significant friction decrease was observed for transverse sliding direction, where values of $0.28,0.3,0.32$ and 0.4 at loads of 50,100, 150 and $200 \mathrm{~N}$ respectively. Based on those readings the sliding condition could be considered as unsafe. The tread width of 2 $\mathrm{mm}$ was still the best one. It seems that the tendency of the tread to form oil wedge increased with increasing tread width so that the area of oil film increased and consequently friction decreased.

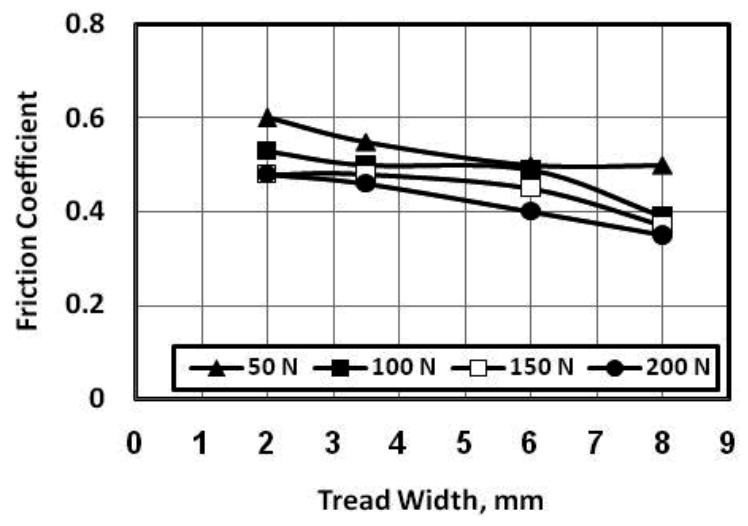

Fig. 10. Friction coefficient of bare foot sliding against oil lubricated pedal pad. Longitudinal direction. 


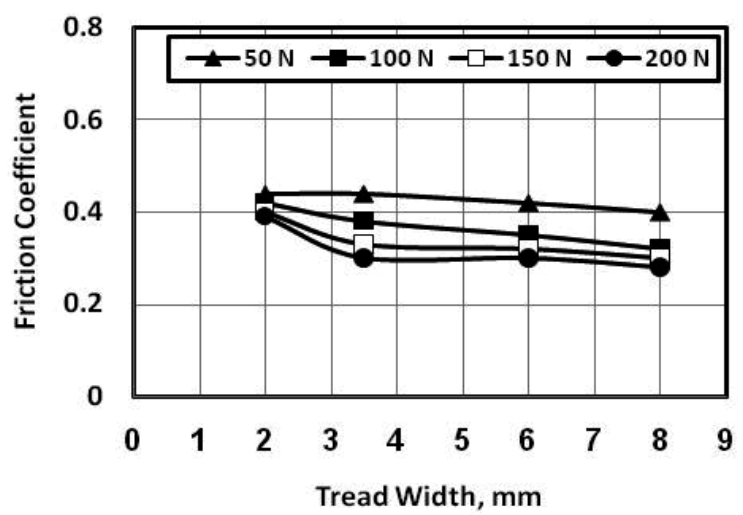

Fig. 11. Friction coefficient of bare foot sliding against oil lubricated pedal pad. Transverse direction.

The results of experiments carried out using rubber shoes sliding against the tested rubber pads are illustrated in Fig. 12-19. At dry sliding, Fig. 12 and 13, friction coefficient displayed relatively lower values than bare foot. This behaviour might be attributed to the relatively higher value of the rubber hardness than the bare foot. Besides, adhesion of bare foot into the pedal pad is stronger than footwear. Sliding in the transverse direction displayed higher friction values than longitudinal one. The minimum friction values were observed for longitudinal direction at 8 $\mathrm{mm}$ tread widths were $0.64,0.61,0.58$ and 0.52 at 50, 100, 150 and 200 $\mathrm{N}$.

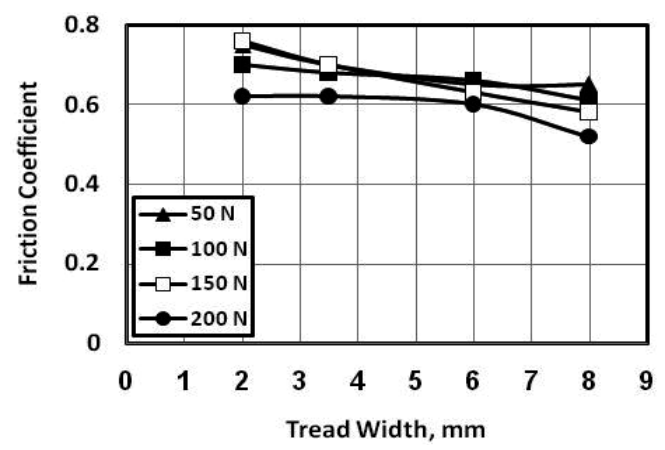

Fig. 12. Friction coefficient of dry sliding of rubber shoes against the pedal pad. Longitudinal direction. 


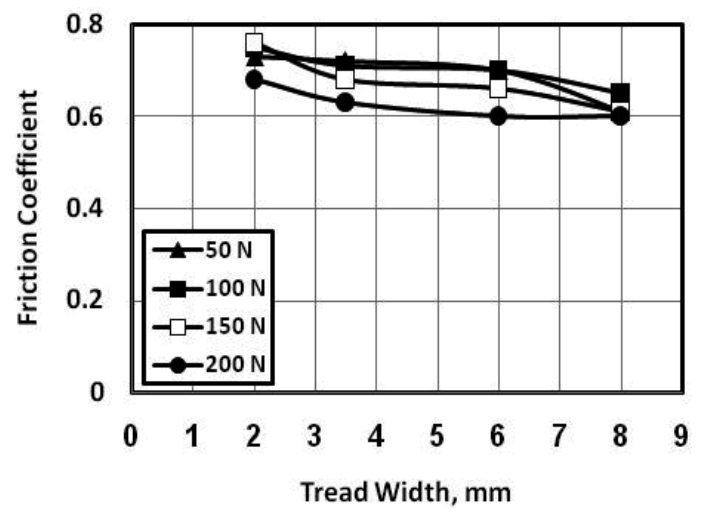

Fig. 13. Friction coefficient of dry sliding of rubber shoes against the pedal pad. Transverse direction.

In the presence of sand particles on the sliding surfaces, the shortest tread width displayed the highest friction, Fig. 14. This behavior is due to the easy escape of sand particles from the contact area through the tread groove. In the transverse direction, Fig. 15, friction was lower than that displayed in the longitudinal one as a result of sand particles embedment in the rubber surface. Consequently, the embedment of sand particles in the foot wear was lower than bare foot. In that condition the tendency of sand particle to roll was higher than to embed and this behaviour caused the friction coefficient to decrease.

Friction coefficient of rubber shoes sliding against water wetted pedal pad in the longitudinal direction is shown in Fig. 16. At $2 \mathrm{~mm}$ tread width, friction coefficient displayed the highest values due to the water leakage from the contact area. The friction values displayed in the transverse direction were relatively lower than that displayed in the longitudinal direction, Fig. 17. Generally, friction values were higher than 0.6 for all values of tread width. Generally, bare foot and footwear showed the same frictional trend. 


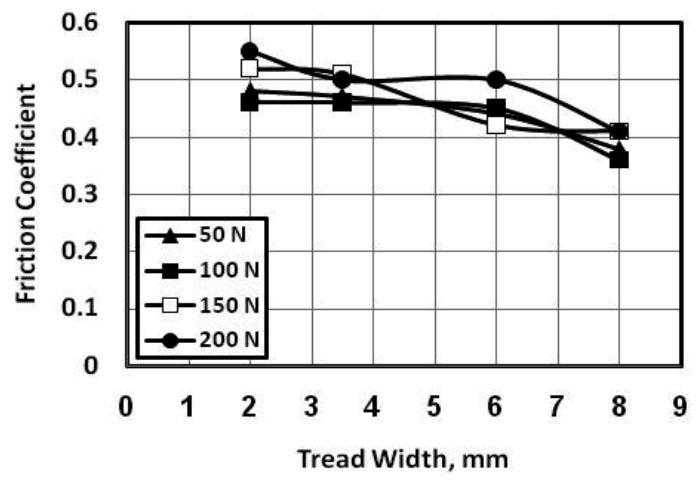

Fig. 14. Friction coefficient of rubber shoes sliding against sand contaminated pedal pad. Longitudinal direction.

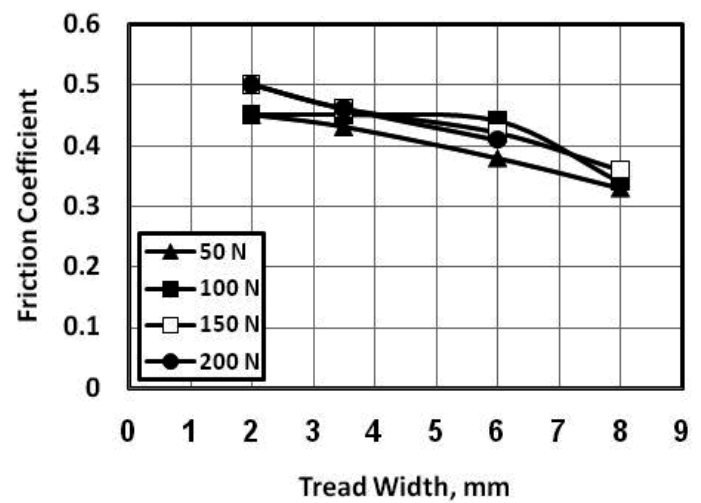

Fig. 15. Friction coefficient of rubber shoes sliding against sand contaminated pedal pad. Transverse direction.

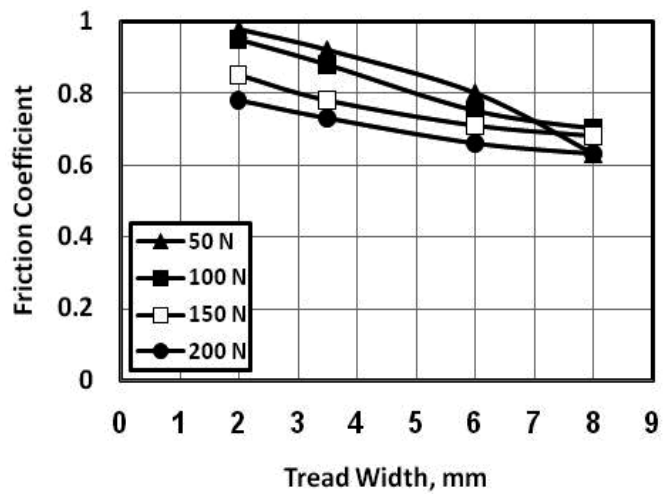

Fig. 16. Friction coefficient of rubber shoes sliding against water wetted pedal pad. Longitudinal direction. 


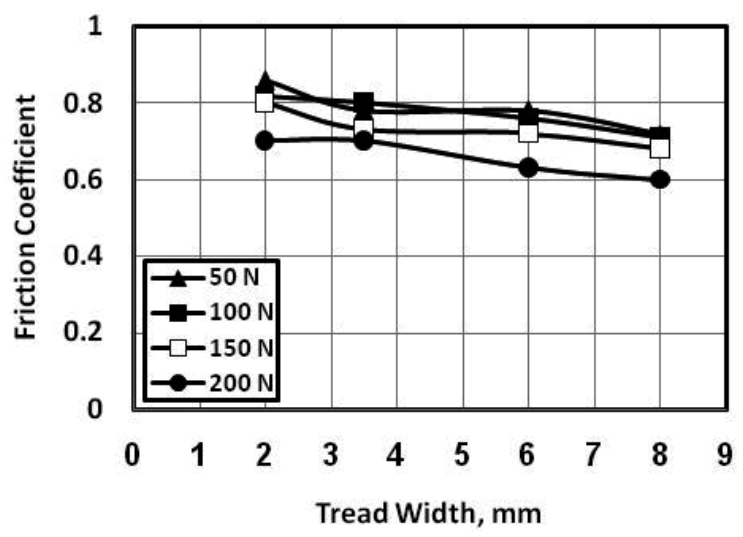

Fig. 17. Friction coefficient of rubber shoes sliding against water wetted pedal pad. Transverse direction.

Sliding against oil lubricated pedal pad in the longitudinal direction, Fig. 18, showed relatively low friction values. As the tread width increased, friction coefficient decreased. Bare foot showed higher friction values than footwear, while in the transverse direction footwear displayed higher friction coefficient than bare foot, Fig. 19. The significant friction decrease might be from the strong adhesion of oil into the sliding surfaces forming oil film covering the contact area, Fig. 20. The direction of sliding had no effect on the values of friction coefficient.

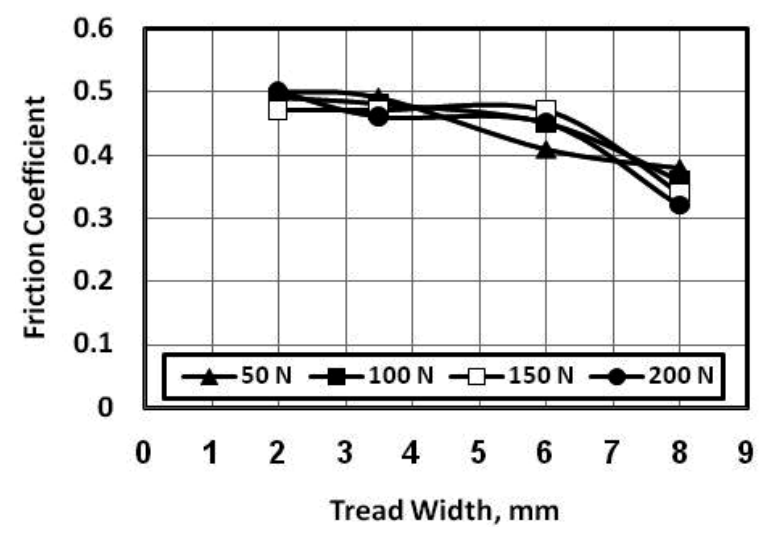

Fig. 18. Friction coefficient of rubber shoes sliding against oil lubricated pedal pad. Longitudinal direction. 


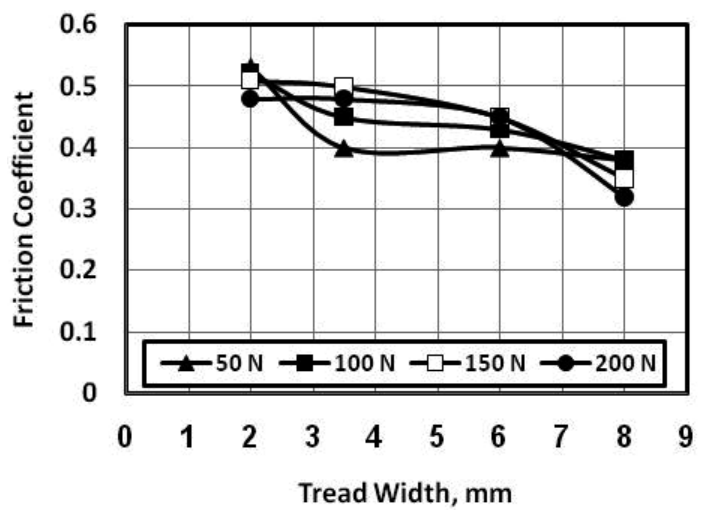

Fig. 19. Friction coefficient of rubber shoes sliding against oil lubricated pedal pad. Transverse direction.

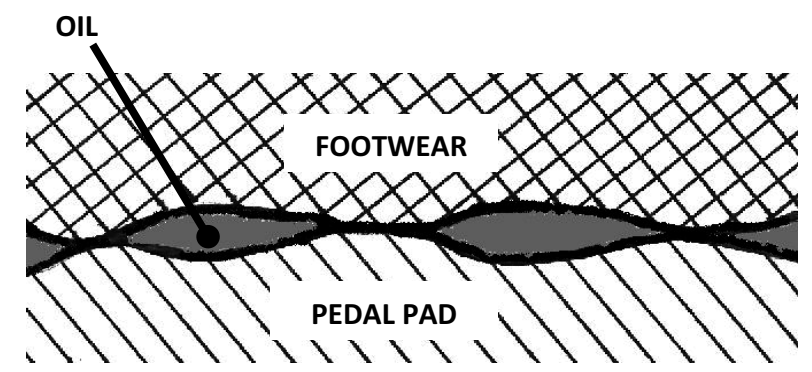

Fig. 20. Sketch of the contact between footwear and pedal pad surfaces lubricated by oil.

\section{Conclusions}

I. From the sliding of bare foot against the pedal pad the following can be concluded:

1- Friction coefficient of dry significantly decreased with increasing the tread width. The sliding direction has no effect on the friction coefficient for the tested pads.

2- In the presence of sand particles separating the two contact surfaces, load had no influence on friction coefficient. Friction coefficient slightly decreased with increasing the tread width.

3- For water wetted pedal pad, friction coefficient displayed higher values than that observed for the condition of presence of sand particles. Friction values showed consistent trend with increasing the tread width. 
4- Friction displayed by oil lubricated pedal pads was the lowest and the sliding condition could be considered as unsafe.

II. For rubber shoes sliding against the tested rubber pads the following can be concluded:

1- At dry sliding, friction coefficient displayed relatively lower values than bare foot. Sliding in the transverse direction displayed higher friction values than longitudinal one.

2- In the presence of sand particles on the sliding surfaces, the shortest tread width displayed the highest friction.

3- Sliding against water wetted pedal pad, the highest values of friction coefficient were displayed by $2 \mathrm{~mm}$ tread width due to the water leakage from the contact area. The friction values displayed in the transverse direction were relatively lower than that displayed in the longitudinal direction.

4- Sliding against oil lubricated pedal pad showed relatively low friction values which were considered as unsafe sliding.

\section{References}

[1] Derler, S., Kausch, F. and Huber, R., "Analysis of factors influencing the friction coefficients of shoe sole materials", Safety Science, 46: 822-832 (2008).

[2] Maeda, K., Bismarck, A. and Briscoe, B., "Effect of bulk deformation on rubber adhesion ", Wear, 263: 1016-1022 (2007).

[3] Samy, A.M., Mahmoud, M.M., Khashaba, M.I. and Ali, W.Y., "Friction of Rubber Sliding Against Ceramics, I. Dry and Water Lubricated Conditions", KGK Kautschuk Gummi Kunststoffe 60. Jahrgang, Nr 607, Juni 2007, pp: 322-327 (2007).

[4] Samy, A.M., Mahmoud, M.M., Khashaba, M.I. and Ali, W.Y., "Friction of Rubber Sliding Against Ceramics, II. Oil And Oil Diluted By Water Lubricated Conditions", $K G K$ Kautschuk Gummi Kunststoffe 60. Jahrgang, Nr 607, December 2007, pp: 693-696 (2007).

[5] Samy, A.M., Mahmoud, M.M., Khashaba, M.I. and Ali, W.Y., "Friction of Rubber Sliding Against Ceramics, III. Sand Contaminating The Lubricating Fluids", KGK Kautschuk Gummi Kunststoffe 60. Jahrgang, Nr 607, January/February 2008, pp: 43-48 (2008).

[6] Ezzat, F.H., Hasouna, A.T. and Ali, W.Y., "Friction Coefficient of Rubber Sliding Against Polymeric Indoor Flooring Materials of Different Surface Roughness", Journal of the Egyptian Society of Tribology, 4(4) January: 37-45 (2007).

[7] Chang, W.R., "The effect of surface roughness on the measurements of slip resistance", International Journal of Industrial Ergonomics, 24(3): 299-313 (1999).

[8] Mohamed, M.K., Samy, A.M. and Ali, W.Y., "Friction Coefficient of Rubber Shoes Sliding Against Ceramic Flooring", September 27-29, 2010, Tribologie Fachtagung, Göttengen, Germany (2010). 
[9] Li, K.W. and Chen, C.J., "The effect of shoe soling tread groove width on the coefficient of friction with different sole materials, floors, and contaminants", Applied Ergonomics, 35: 499-507 (2004).

[10] El-Sherbiny, Y.M., Samy, A.M. and Ali, W.Y., "Friction Coefficient of Rubber Sliding Against Dusty Indoor Flooring", Journal of the Egyptian Society of Tribology, 7(2) April: 11-25 (2010).

[11] Li, K.W., Wu, H.H. and Lin, Y.C., "The effect of shoe sole tread groove depth on the friction coefficient with different tread groove widths, floors and contaminants", Appl. Ergon., 37: 743-748 (2006).

[12] Li, K.W., Hsu, Y.W., Chang, W.R. and Lin, C.H., "Friction measurements on three commonly used floors on a college campus under dry, wet, and sand covered conditions", Saf. Sci., 45(9): 980-992 (2007).

[13] Li, K.W., Chang, W.R., Leamon, T.B. and Chen, C.J., "Floor slipperiness measurement: friction coefficient, roughness of floors, and subjective perception under spillage conditions", Saf. Sci. 42: 547-565 (2004).

[14] Chang, W.R., "The effects of slip criteria and time on friction measurements", Saf. Sci., 40: 593-611 (2002).

[15] Li, K.W., Chang, W.R., Wei, J.C. and Kou, C.H., "Friction measurements on ramps using the Brungraber Mark II slipmeter", Saf. Sci., 44: 375-386 (2006).

[16] Chang, W.R. and Matz, S., "The slip resistance of common footwear materials measured with two slip-meters", Applied Ergonomics, 32: 540-558 (2001).

[17] Grönqvist, R., "Mechanisms of friction and assessment of slip resistance of new and used footwear soles on contaminated floors", Ergonomics, 38(2): 224-241 (1995).

[18] [18] Leclercq, S., Tisserand, M. and Saulnier, H., "Tribological concepts involved in slipping accidents analysis", Ergonomics, 38(2): 197 - 208 (1995).

[19] Manning, D.P. and Jones, C., "The effect of roughness, floor polish, water, oil and ice on underfoot friction: Current safety footwear solings are less slip resistant than microcellular polyurethane", Applied Ergonomics, 32: 185-196 (2001).

[20] Strandberg, L., "The effect of conditions underfoot on falling and overexertion accidents", Ergonomics, 28(1): 131-147 (1985).

[21] Chang, W.R. and Matz, S., "The slip resistance of common footwear materials measured with two slipmeters", Applied Ergonomics, 32: 540-558 (2001).

[22] Grönqvist, R., "Mechanisms of friction and assessment of slip resistance of new and used footwear soles on contaminated floors", Ergonomics, 38(2): 224-241 (1995).

[23] Leclercq, S., Tisser, M. and Saulnier, H., "Tribological concepts involved in slipping accidents analysis", Ergonomics, 38(2): 197-208, (1995).

[24] Al-Osaimy, A.S. and Ali, W.Y., "Friction Coefficient of Bare Foot and Footwear Sole Sliding Against Brake Pedal Pads", Under Publication (2011). 
تأثير سمك النتوءات العرضية لسطح دواسة المكابح على معامل الاحتكالك الناتج من القدم الحافية والحذاء ذي النعل المطاطي

\section{علي سعد العصيمى، و وحيد يسري علي}

كلية الهندسة، جامعة الطائف، الطائف، المدلكة العربية السعودية

الاستخلص. عند ضغط القدم على دواسة المكابح يجب أن تكون قوة الاحتكاك كبيرة بالدرجة الكافية التي تمنع انزلاق القدم من على دواسة القابة

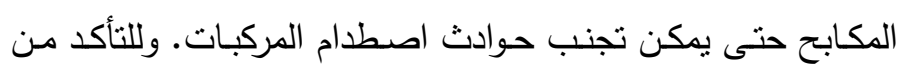
ذلك يجب قياس معامل الاحتكاك الناتج من احتكاك الحذاء ودواسة

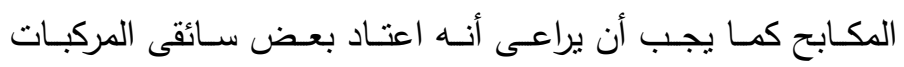

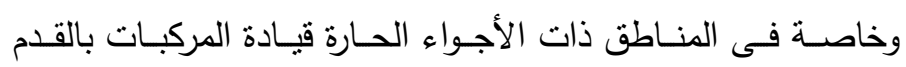

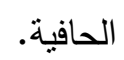

يناقش هذا البحث تأثير عرض التعرجات العرضية لسطح

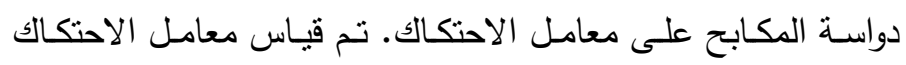

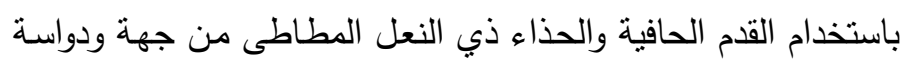

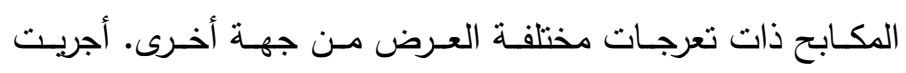

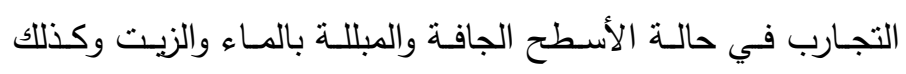

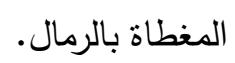

بينت التجارب أن معامل الاحتكاك للقدم الحافية عند انزلاقها

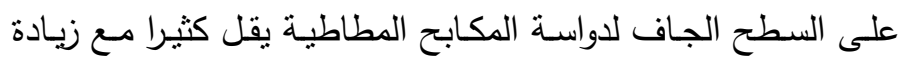

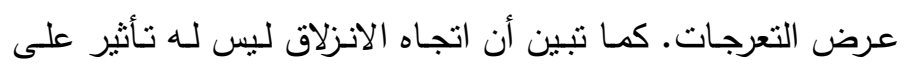

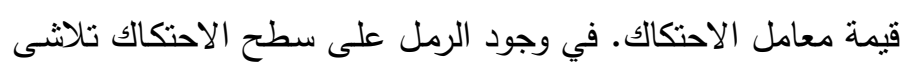


تأثثير الحمل كما قل معامل الاحتكاك مع زيادة عرض التعرجات. في حالة وجود الماء على سطح الانزلاق سجل معامل الاحتكاك قيما أعلى من مثيلاتها في حالة وجود الرمال ولكنه

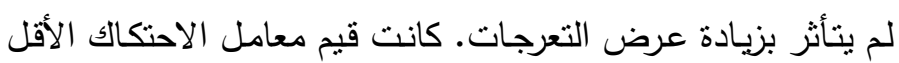
عند تلوث سطح الاحتكاك بالزيت. بالنسبة لاختبارات قياس معامل الاحتكالك الناتج من انزلاق

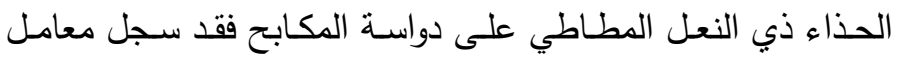

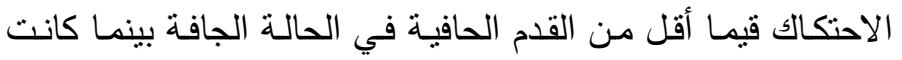
القيم أعلى في حالة الانزلاق العرضي. في حالتي وجود الرمال والماء

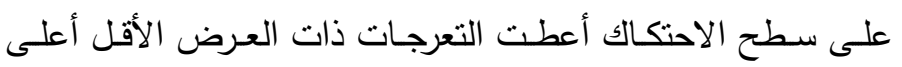

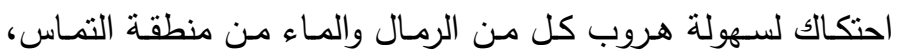
كذلك قل معامل الاحتكالك في حالة الانزلاق في الاتجاه العرضي.

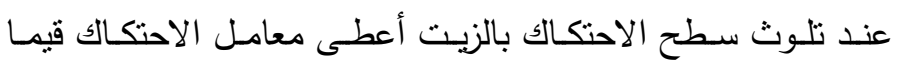

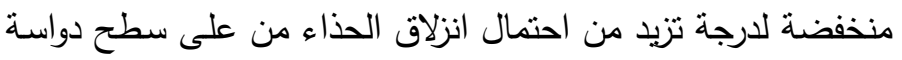

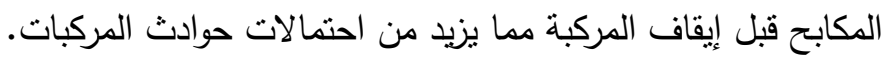

